6
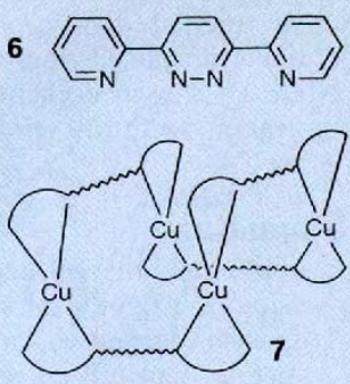

FIG. 3 The ligand 6 used by Osborne and colleagues to make a molecular box, 7

spontaneous and correct assembly of altogether eleven particles. ..."

These studies fit into a wider framework of studies involving the metaldirected construction of supramolecular architectures. Whereas Lehn's group has demonstrated the use of a single type of metal to assemble to different ligands, we have demonstrated the ability of one type of ligand to assemble two different metal ions into heteronuclear doublehelical arrays ${ }^{5}$. The attractive triplehelical motif of the cylinder 5 has been the target of the group of Williams in Geneva $^{6}$. It turns out that subtle factors control the assembly of double- or triplehelices in a particular metal-ligand system. This observation is borne out by the unexpected helical twisting of 5 .

It is perhaps appropriate to mention a microstructure that has recently been described by the group of Osborn, also in Strasbourg?. Compound 6, which bears an obvious similarity to 4 , reacts with copper(I) to self-assemble a molecular box containing four copper centres, compound 7 (Fig. 3). This compound may be seen as an electron reservoir, and each of the copper(I) centres may be sequentially oxidized to copper(II) without the disruption of the supramolecular architecture. Such compounds provide an entry to new types of microstructures which imitate electronic components. Compound 7 may be thought of as the seed of a molecular accumulator or capacitor which may store and then release up to four electrons to a molecular wire.

Edwin C. Constable is in the University Chemical Laboratory, University of Cambridge, Lensfield Road, Cambridge CB2 1EW, UK.

1. Baxter, P., Lehn, J.-M., DeCian, A. \& Fischer, J. Angew. Chem. Int. Ed. Engl. 32, 69-72 (1993).

2. Vögtle, F. Supramolecular Chemistry (Wiley, Chichester 1991).

3. Constable, E. C. Tetrahedron 48, 10013-10059 (1992)

4. Dietrich-Buchecker, C. O. \& Sauvage, J.-P. Bioorganic Chem. Frontiers 2, 197-248 (1991).

5. Constable, E. C. \& Walker, J. V. J. chem. Soc., chem. Commun., 884-886 (1992).

6. Piguet, C. et al. J. Am. chem. Soc. 114, 7440-7451 (1992).

7. Youinou, M. T., Rahmouni, N., Fischer, J. \& Osborn, J. A. Angew. Chem. Int. Ed. Engl. 31, 733-735 (1992)

\section{Ion-channel studies blossom}

LEHN'S homage to nature is even more obvious In a second paper, describing the synthesis of artificlal lon channels that can be incorporated into a lipid membrane resembling a cell wall (M. J. Pregel, L. Jullen \& J.-M. Lehn Angew. Chem. Int. Ed. Engl. $31,1637-1640 ; 1992)$. The transport of electrons across membranes constlitutes the critical step In photosynthesis, and hence the key step in the

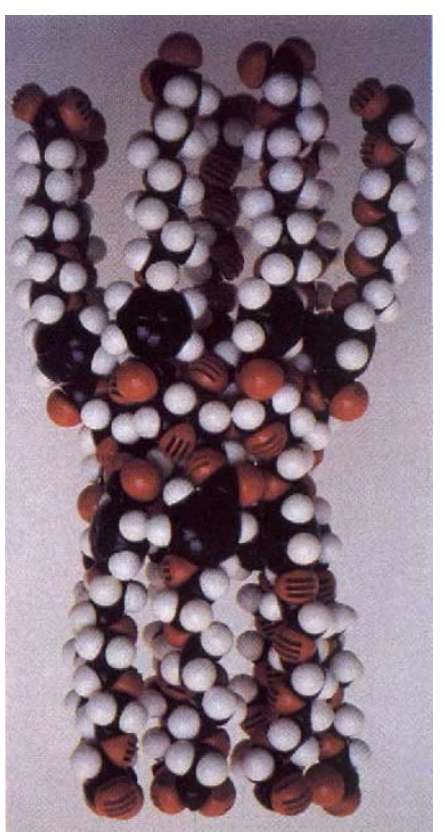
production of food and of energy. Simllarly, the transmembrane transport of lons is the critical step in metabolism for the controlled production of energy and for the firing of nerve signals. Ions are carrled from one side of a membrane to another by one of two processes: by forming complexes with some other agent which can diffuse across the membrane, acting as a shuttle or diffusive carrler; or a large molecule which spans the breadth of the membrane produces a pore through which the lons can easily penetrate.

Lehn and colleagues have made a new class of artiflclal lon channels by grafting poly(oxyethylene) or polymethylene chains of various lengths onto macrocyclic rings. The authors call their compounds 'bouquet' molecules, as the long chains emanating from the central annulus (with a little imagination) resemble long-stemmed roses protruding from a vase. They have prepared two such molecules, one with a ring-like crown ether as the central ring, the second with a modIfled cyclodextrin core (resembling a truncated cone).

The authors prepared their lipld vesicles, resembling cells, in lithium chloride solution. Once these had formed, sodlum chloride was added to the solution, so that the composition inside and outside the cells was different. NMR spectroscopy showed that mixing between the two samples was much faster with the bouquet molecules in the vesicle walls. The simplest interpretation is that the metal cations become complexed at one end of the pore, carried through the channel and released at the opposite end.

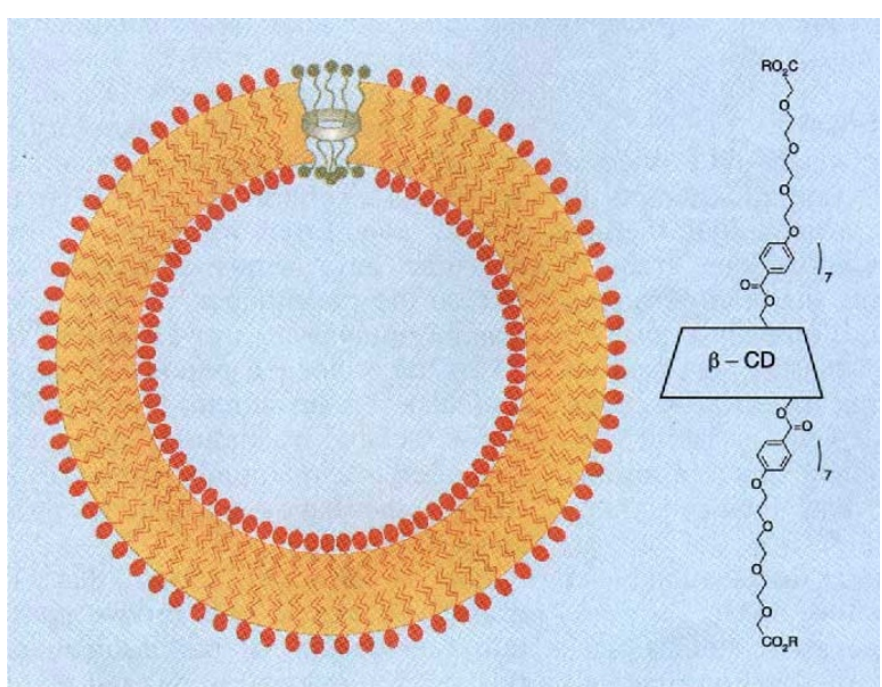

Top: molecular model of the bouquet molecule based on cyclodextrin $(\beta-C D)$. Left, structure of the same molecule, showing just two stems. Incorporated into a vesicle wall (far left), the molecule allows rapid interchange of alkali metal atoms between the 'cell' interior and exterior.

Many possibilities can be Imagined for using such molecules in studying mechanisms of lon transport and for determining the effect of including other small and large molecules on the effectiveness of cross-membrane channelling. Because these artificial systems are amenable to synthetlc manipulation, one could design different lengths of 'bouquets' and choose the best 'flowers' and 'stems' to control selectlve lon transport to include even non-alkall metals or larger organic cations.

Marye Anne Fox 